\title{
Urgences
}

\section{Dans ce pays d'air où la laine est essentielle}

\section{Lise Lessard}

Numéro 5, 3e trimestre 1982

URI : https://id.erudit.org/iderudit/025070ar

DOI : https://doi.org/10.7202/025070ar

Aller au sommaire du numéro

Éditeur(s)

Urgences

ISSN

0226-9554 (imprimé)

1927-3924 (numérique)

Découvrir la revue

Citer ce document

Lessard, L. (1982). Dans ce pays d'air où la laine est essentielle. Urgences, (5),

5-6. https://doi.org/10.7202/025070ar d'utilisation que vous pouvez consulter en ligne.

https://apropos.erudit.org/fr/usagers/politique-dutilisation/ 


\section{DANS CE PAYS D'AIR OU் LA LAINE EST ESSENTIELLE}

Quand les feuilles seront tombées, et que les demoiselles iront les ramasser... que dans le bois désert le loup aura lavé ses dents, chaussé ses bottes et pris son déjeûner... que la gardienne de l'été aura chanté sa dernière berceuse, descendu l'escalier du grenier et bien fermé la porte à clé... que le soir cognera plus tôt aux carreaux de la mer... et que l'odeur sucrée - de toutes les herbes de juillet - aura confessé ses péchés aux écureuils distraits, recousant les boutons de leurs manteaux d'hiver!

Quand se regarderont dans les flaques de pluie, les couleurs délavées qu'aura sorties le ciel à coups de pied légers... quand les cloches referont sursauter les petits coeurs dans les cours des récréations... que s'en ira jouer dans une autre fanfare l'amour qui aura bien trop froid pour pouvoir se baigner...

"allons rapproche-toi de moi par le dedans

continuons la route très lentement"1

...oui .... ...promenons-nous encore ensemble!

Arrêtons-nous parfois. Déterrons nos paroles. Échangeonsles comme font les enfants avec leurs billes. Fermons nos yeux... et comptons jusqu'à cinq! N'ayons pas peur d'être complices!... Dans ce pays d'air où la laine est essentielle, abritons-nous de nous, avec nos mots à nous... Te souviens-tu des belles choses qu'on s'est dites, déjà?... Une fois c'était:

"il faut être la vie tenant un bouleau jaune entre ses

doigts, et des cailloux roses de source froide entre ses pattes d'oiseau de passage..." 2

et puis une autre:

"Quelqu'un m'attend loin derrière la colline

son chemin comme le mien une étoile diffuse ${ }^{3 \prime \prime}$

... chuchotons entre nous un paquet d'autres histoires. Jouons encore à s'éblouir, puisqu'on se bat toujours et que l'on aime encore, et que rôdent partout les mêmes vieux fantômes, les mêmes peurs... passant si près de nous qui avançons toujours ensemble, racontons que "la nuit a toujours sa longue main qui danse $^{4, " . . . ~ R a s s u r o n s-n o u s ~ . . . ~ F a i s o n s ~ d e ~ p e t i t s ~ t r o u s ~ s u r ~ l a ~ p a r o i ~}$ 
de nos solitudes... prenons-nous par la main ... disons-nous des secrets!

Ferme les yeux, compte jusqu'à cinq... puis ouvre-les ... II y aura ici, qui glissent sur les pages, des nostalgies d'enfance, comme des souvenirs pesés sur d'anciennes balances à bonbons ... le croquis de sept grandes personnalités découvertes dans le plus banal quotidien, dans le petit hôtel désuet plein d'ombres bigarrées... cette enfant triste qui joue à sautons-moutons, qui s'inquiète et qui crie des bêtises aux mensonges, la narguant derrière ses lunettes très rondes ... et il y aura dans la pénombre, un poète interrogeant le vide de sa cage, décortiquant l'attente dans le noir et nommant l'insondable... un autre veut cracher sur les dieux inventés, pourchasser tous les spectres d'un pays béant de déchirures, rêvant de s'y loger dans une paix comme dans un sommeil.

... il y aura des contes fantastiques, des récits insolites! Des regards comme dans des miroirs pour mieux se voir! ... et une femme lasse faisant des pieds-de-nez à ses vieilles insignes d'ange et de madone ... une autre aura sculpté, dans la respiration même du poème, sa belle évidence charnelle - chacun des sens exécutant sa propre partition dans la symphonie de sa naissance ... et puis j'ouvre moi-même ce livre où nous fouillerons côte à côte, avec des goûts de prendre et de grandir encore, en dépit des défaites et de nos différences - de femmes et d'hommes ensemble.

Laisse-toi prendre ... et reçois-nous dans tes silences ... Ne jouons plus de la cachette entre nous ...

"allons rapproche-toi de moi par le dedans soyons com-

plices du même vent qui nous habite" 5

... oui ... ... promenons-nous ici ensemble ... une cinquième fois!

Lise Lessard pour le Comité de direction

\footnotetext{
1 Alain St Yves, URGENCES numéro 3, p. 35

2 Huguette Légaré, URGENCES numbero 4, p. 15

3 James Paulin, UGENCES numéro 2, p. 59

4 Michelle Dubois, UGENCES numéro 1, p. 100

5 Alain St-Yves, URGENCES numéro 3, p. 36
} 